\title{
Generation Mechanism of Spiciness Anomalies: An OGCM Analysis in the North Atlantic Subtropical Gyre
}

\author{
Audine laurian, Alban Lazar, And Gilles Reverdin \\ Laboratoire d'Océanographie et du Climat: Expérimentation et Approche Numérique, Institut Pierre Simon Laplace, \\ Unité Mixte de Recherche, CNRS-UPMC-IRD, Paris, France
}

(Manuscript received 13 August 2007, in final form 18 September 2008)

\begin{abstract}
Oceanic teleconnections between the low and midlatitudes are a key mechanism to understanding the climate variability. Spiciness anomalies (density-compensated anomalies) have been shown to transport temperature and salinity signals when propagating along current streamlines in the subtropical gyres of the Atlantic and Pacific Oceans. The generation mechanism of spiciness anomalies in the North Atlantic subtropical gyre is investigated using an analytical model based on the late-winter subduction of salinity and temperature anomalies along isopycnal surfaces. The keystone of this approach is the change of the coordinates frame from isobaric to isopycnic surfaces, suited for subduction problems. The isopycnal nature of spiciness anomalies and the use of a linear density equation allows for the analytical model to depend only upon surface temperature and salinity anomalies, the mean thermocline currents, and the surface density ratio. This model clarifies and above all quantifies the mechanism by which surface temperature and salinity anomalies are modulated by density ratios to produce fully different isopycnal temperature and salinity anomalies.

A global run from the ocean GCM (OGCM) Océan Parallélisé (OPA) over the period 1948-2002 provides the reference data in which the North Atlantic subtropical thermocline spiciness variability is analyzed. Two EOF modes are sufficient to explain half of the low-frequency variability in the OGCM: one is maximum over the northeastern subtropics, and the other is in the central basin. The analytical model reproduces well the spatial pattern, amplitude, and sign of these two main modes. It confirms that the two centers of action of the anomalies are conditioned by the surface density ratio, the first corresponding to null salinity gradients and the second to near-density-compensated temperature gradients. Considering that the analytical model has good skills at reproducing the decadal variability of the OGCM spiciness anomalies in the permanent thermocline, it is believed that this is an interesting tool to understand and forecast the ventilation of the North Atlantic subtropical gyre at this time scale.
\end{abstract}

\section{Introduction}

A variable called spiciness was introduced three decades ago in order to characterize water masses and intrusions (Munk 1981; Jackett and McDougall 1985). Water masses can either be characterized by their temperature and salinity or by their spiciness and density. To a first-order approximation a spiciness anomaly (noted $\mathrm{d} \pi$ ) along a given time-varying surface of constant potential density referenced to the surface pres-

Corresponding author address: Audine Laurian, Laboratoire d'Océanographie et du Climat: Expérimentation et Approche Numérique (LOCEAN), Université Pierre et Marie Curie, 4 Place Jussieu, Tour 45-55 4ème étage, Case 100, Paris, CEDEX 75252, France.

E-mail: audine.laurian@locean-ipsl.upmc.fr sure (called isopycnal surface and noted as $\sigma$ ) is a linear combination of temperature and salinity anomalies modulated by the thermal contraction coefficient and the haline expansion coefficient, respectively $\left(d \pi_{\sigma}=\beta d S_{\sigma}+\right.$ $\left.\alpha d T_{\sigma}\right)$. Assuming that the spatial and temporal variations of the two coefficients are small (Tailleux et al. 2005), the temperature and salinity anomalies are proportional on a given isopycnal surface, where $d \sigma=\beta d S_{\sigma}-\alpha d T_{\sigma}=0$. It is therefore equivalent to address the generation mechanism of a spiciness anomaly, either that of an isopycnal salinity anomaly [ISA; ISA $=d S_{\sigma}=(2 \beta)^{-1} d \pi_{\sigma}$ ] or that of an isopycnal temperature anomaly [ITA; ITA $=d T_{\sigma}=$ $\left.(2 \alpha)^{-1} d \pi_{\sigma}\right]$.

To a first-order approximation, spiciness anomalies behave as dynamically passive tracers that are advected by the currents in the thermocline (Nonaka and Xie 
2000; Lazar et al. 2001; Yeager and Large 2004; Luo et al. 2005; Johnson 2006; Laurian et al. 2006, hereafter LLR). In the North Atlantic Ocean, spiciness anomalies that are generated in the salinity maximum water (SMW) region propagate at the current speed and emerge close to $30^{\circ} \mathrm{N}$ in the Gulf Stream (LLR). There, they can interact with the atmosphere and not be density compensated anymore, therefore impacting the sea surface density. Late-winter subduction was suggested to be the mechanism responsible for setting the characteristics of the spiciness anomalies in the thermocline, although the details of the generation process of these signals were not the focus of the study.

Several hypotheses have been made about the generation of spiciness anomalies. According to Schneider (2000), the positive spiciness anomalies are generated by anomalous advection across the mean isopycnal temperature-salinity front. Yeager and Large $(2004,2007)$ suggested that positive spiciness anomalies were generated by a late-winter subsurface injection process expected wherever large, unstable salinity gradients are present in conjunction with weak stratification and strong mixing in winter. This injection process was also identified by Luo et al. (2005), and they showed that in addition the spiciness anomalies can also be created by subduction along outcropping isopycnal surfaces, even though this process alone is not enough to explain the equatorial decadal variability. Kessler (1999), however, could not link the observed trends in isopycnal salinity to upstream changes at winter density outcrops in the Pacific Ocean. As was first suggested by Church et al. (1991) and by Bindoff and McDougall (1994), results from an analytical model developed by Nonaka and Sasaki (2007) show that cool sea surface temperature anomalies in the eastern subtropical South Pacific can generate the displacement of a density outcrop line inducing a warm and salty subducted anomaly on the isopycnal surface. The goal of this paper is to better understand the ventilation of the thermocline by spiciness anomalies in the North Atlantic subtropical gyre, showing that these anomalies are generated by a latewinter subduction mechanism.

We describe the ocean GCM (OGCM) used here in section 2. It is validated and the surface salinity and temperature anomalies are briefly analyzed in the generation region of the spiciness anomalies. We describe the methodology to define spiciness anomalies in section 3. An analytical model is developed to understand and forecast the surface generation of these spiciness anomalies. The analytical anomalies are compared to the OGCM ones and they are discussed with respect to the late-winter surface anomalies in section 4. Finally, the main results are summarized in section 5 .

\section{Model and decadal variability of the SSS and SST anomalies in the formation region of the spiciness anomalies}

The global OGCM used here is the version 8.1 release of Océan Parallélisé (OPA; Madec et al. 1998). The eddy parameterization scheme of Gent and McWilliams (1990) is applied poleward of $20^{\circ}$ and vertical mixing is achieved using the turbulent kinetic energy (TKE) scheme of Blanke and Delecluse (1993). As in LLR, the model configuration has a zonal resolution of $2^{\circ}$, and a meridional resolution that ranges from $0.5^{\circ}$ at the equator to $2^{\circ} \times \cos$ (latitude) poleward of $20^{\circ}$. There are 31 fixed vertical levels with $10-\mathrm{m}$ spacing at the surface and increasing to $500 \mathrm{~m}$ in the deepest ocean. The model is implemented without double diffusion, which does not allow the quantification of the decrease of the spiciness anomalies resulting from salt fingering and associated vertical mixing evidenced in the Argo float data analyzed by Johnson (2006). Surface heat fluxes are calculated using bulk formulas based on daily National Centers for Environmental Prediction-National Center for Atmospheric Research (NCEP-NCAR) reanalyses (Kalnay et al. 1996) over the period of 1948-2002, which allows for the investigation of interannual to decadal time scales. During the spinup, the surface boundary condition for freshwater fluxes is a relaxation of salinity to annual mean values from the Boyer et al. (1998) climatology with a restoration time of 12 days. This flux is applied as a flux correction in the model experiment we use so that the sea surface salinity (SSS) can freely evolve in response to the ocean's variability and the freshwater fluxes from NCEP. Monthly averaged fields from 5-day output of this simulation are used because we are interested in the first-order seasonal and interannual mechanisms that are responsible for the generation of the spiciness anomalies.

We pay a particular attention to the spiciness anomalies generated in the SMW region in the North Atlantic Ocean. As shown by Church et al. (1991), the generation of these anomalies is closely linked to the surface conditions that characterize the generation region. This area has been previously defined by LLR in the same OGCM using lagged correlations between the SSS anomalies and the subsurface salinity anomalies along the isopycnal surface characterized by potential density $1026 \mathrm{~kg} \mathrm{~m}^{-3}$ averaged at the entrance of the Gulf of Mexico. Lagged correlation was the highest in the region of $22^{\circ}-28^{\circ} \mathrm{N}, 20^{\circ}-30^{\circ} \mathrm{W}$, which was shown to be close to the upstream surface origin of this subducted water. This region is referred to as the formation region. 
a)

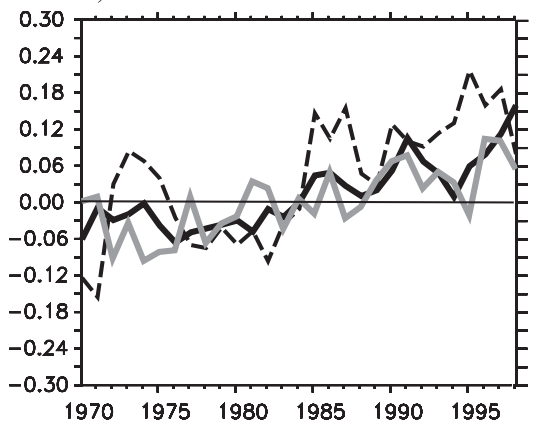

b)

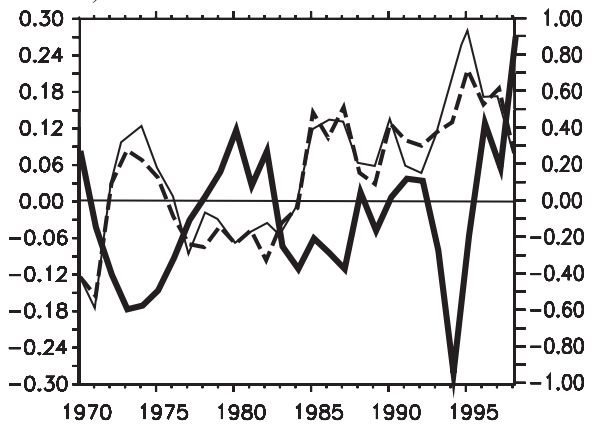

FIG. 1. (a) Winter [January-March (JFM)] sea surface salinity anomalies averaged in $22^{\circ}-28^{\circ} \mathrm{N}$, $20^{\circ}-30^{\circ} \mathrm{W}$, in the OGCM (full, black) and in the observations of Reverdin et al. (2007) (full, gray). The OGCM isopycnal salinity anomalies during the month following that of maximum mixed layer depth, at the closest depth from the mixed layer depth where they are defined, are dashed. (b) Winter (JFM) sea surface temperature anomalies in the OGCM (full, thick). The OGCM isopycnal temperature anomalies during the month following that of maximum mixed layer depth, at the closest depth from the mixed layer depth where they are defined, are shown (full, thin) and the dashed line is the same as in (a). The scales are in (left) psu and (right) ${ }^{\circ} \mathrm{C}$.

The atmospheric forcings are relatively good for the period 1948-2002 and allow for realistic sea surface temperature (SST) anomalies (not shown). The errors and uncertainties in the precipitation $(P)$ require more examination. The late-winter SSS anomalies in the OGCM are compared to the observed SSS anomalies starting in 1970 and analyzed by Reverdin et al. (2007) in the formation region (Fig. 1a). Although the simulated SSS anomalies are about 0.03 psu higher on average than the observed ones, their interannual variability is well reproduced between 1983 and 1998. Earlier, forcing errors or sparser data are likely explaining the apparent lack of realism of the SSS anomalies. Regarding lower-frequency variability, the SSS anomalies underwent an increase of approximately 0.15 psu between 1970 and 1998, mainly resulting from intensified trade winds (an increase of approximately $0.5 \mathrm{~m} \mathrm{~s}^{-1}$ during this period, not shown). Such intensification induces both an enhanced evaporation rate $(E)$ and an enhanced Ekman transport. The effects of each of these forcings on the long-term variability of the SSS anomalies in the formation region are comparable to those controlling the seasonal cycle (appendix A). The enhanced $E-P$ rate (increase of approximately $4 \mathrm{~cm} \mathrm{yr}^{-1}$ over the 28 -yr period, not shown) is in agreement with the observations of Curry et al. (2003) and with the model study of Latif et al. (2000). Its amplitude dominates that of the Ekman current advection (increase of $0.2 \mathrm{~cm} \mathrm{yr}^{-1}$ over the 28 -yr period, not shown), indicating that the increase in $E-P$ is responsible for the decadal variability of the SSS anomalies in the formation region. The multidecadal trend of the subducted ISAs for the month following that of maximum mixed layer depth (MLD) and at the closest depth from the MLD where they are defined (dashed black line on Figs. 1a,b) resembles that of the late-winter simulated SSS anomalies (thick black line on Fig. 1a), as was shown by LLR. To understand this relationship, suppose that a freshening of the surface waters occurs in the formation region with no sea surface temperature variation. This freshening lightens the surface waters leading to a poleward displacement of the outcropping isopycnal surfaces. The resulting salinity along the isopycnal surfaces outcropping in the formation region is fresher than the initial SSS because the isopycnal surfaces came from an area closer to the intertropical convergence zone (ITCZ) region, which is mainly controlled by precipitation. The resulting subducted ISA is thus negative. Similarly, the subducted ISAs appear to vary most of the time in opposition of phase with the late-winter SST anomalies (Fig. 1b), except for the early and the late 1990s. Note that the variability of the ISAs and that of the ITAs are very similar over the period of 1970-98 (dashed and thin full lines on Fig. 1b), meaning that the effects of the nonlinearities of the density can be neglected and the coefficient $\alpha \beta^{-1}$ can be considered as constant over this period. In the next section this relationship between SSS anomalies, SST anomalies, and subducted spiciness anomalies is analyzed.

\section{The analytical model}

a. Effect of sea surface temperature and salinity perturbations on the location of outcropping isopycnals

A perturbation of the sea surface density (noted SSDA) can be approximated by a linear combination 
a)
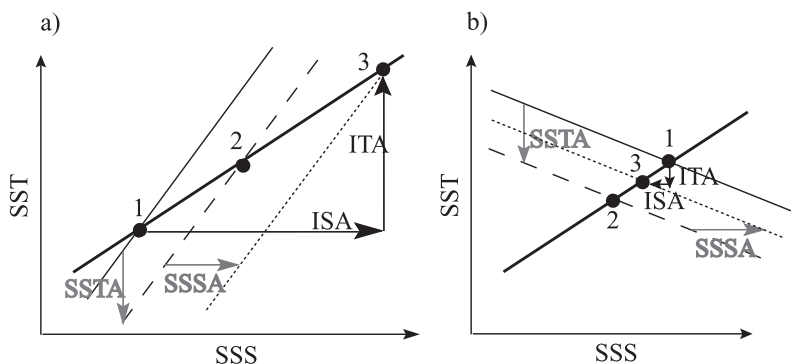

FIG. 2. Schematic temperature-salinity diagrams of surface waters in a region where salinity and temperature gradients have the (a) same and (b) opposite signs. The thick black line represents the linearized density of the surface waters. The thin full line represents the linear fit of the water mass characteristics. Its slope is given by the value of the density ratio in the region. When a surface cooling occurs the water mass characteristics are modified and the linear fit of the new characteristics is dashed. When a surface salinification occurs simultaneously the water mass characteristics are again modified (dotted). The associated isopycnal surface characteristics are indicated by the numbers. The temperature and salinity anomalies along the outcropping isopycnal surface resulting from the cooling and the salinification (ITA and ISA) are highlighted by the black arrows (adapted from Bindoff and McDougall 1994).

of a SSS anomaly (SSSA) and a SST anomaly (SSTA) according to the linearized equation of state of the density

$$
\operatorname{SSDA}=\beta S S S A-\alpha \text { SSTA } .
$$

A local perturbation of the sea surface density induces the displacement of the outcropping isopycnal in a region of varying horizontal gradients of SST and SSS. Figure 2 illustrates the modulations of the characteristics of the surface isopycnal anomalies in a region where horizontal gradients of SST and SSS have the same sign (Fig. 2a) and in a region where they have opposite signs (Fig. 2b). In the first situation, a simultaneous cooling and salinification, for example, of the surface waters induce a warming and an even stronger salinification on the outcropping isopycnal (Fig. 2a). In the second situation, the same cooling and salinification of the surface waters induce a weaker cooling and a freshening on the outcropping isopycnal (Fig. 2b). The key ingredient in establishing the relationships between the Eulerian and the isopycnal surface anomalies is the relative importance of the temperature and salinity variations in setting the density perturbation.

The displacement of the outcropping isopycnals (noted dl) induced by density perturbations is defined with respect to the monthly mean location of the isopycnals over the period of 1948-2002. The amplitude of this displacement is computed as the sea surface density anomaly scaled by the Euclidean norm of the horizontal
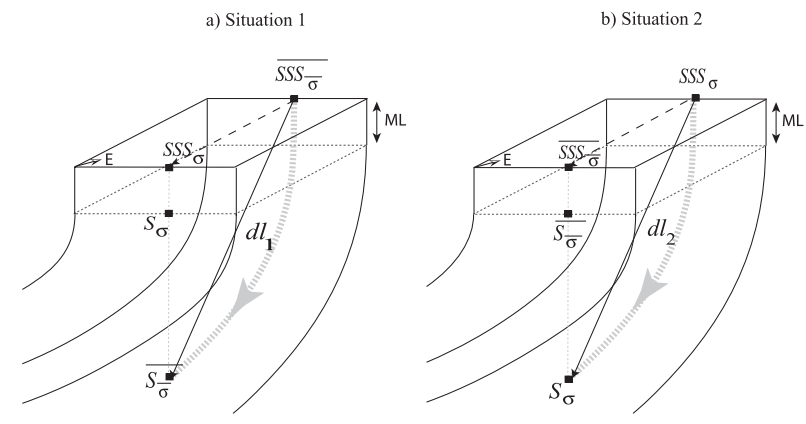

FIG. 3. Schematic representation of the salinity and the mean salinity at the surface (respectively, $\mathrm{SSS}_{\sigma}$ and $\overline{\mathrm{SSS}_{\bar{\sigma}}}$ ) and in the thermocline (respectively, $\mathrm{S}_{\sigma}$ and $\overline{S_{\bar{\sigma}}}$ ) when the mean isopycnal surface outcrops poleward of the interannual isopycnal surface for (a) that month (referred to as situation 1 in the text) and (b) conversely (referred to as situation 2 ). The corresponding surface salinity anomaly $\left(\mathrm{SSSA}_{\sigma}\right)$ is defined by the difference between the two surface signals and the subsurface salinity anomaly (ISA ${ }_{\sigma}$ ) is defined by the difference of the two subsurface signals, as defined in section $3 b$. The displacements $\left(\mathbf{d l}_{1}\right.$ and $\left.\mathbf{d l}_{2}\right)$ of the isopycnal surface $\sigma$ with respect to the mean position of the outcropping isopycnal surface $\bar{\sigma}$ are denoted by the full black arrows. The thick dashed gray curves and associated arrows denote the path of the particles on the deepest isopycnal surface within the thermocline. ML stands for mixed layer. The same schematic holds for temperature signals.

gradients of sea surface density in the vicinity of the surface perturbation,

$$
\|\mathbf{d l}(t)\|=-\frac{\operatorname{SSDA}(t)}{\|\nabla \overline{\operatorname{SSD}}(t)\|}=-\frac{\operatorname{SSD}(t)-\overline{\operatorname{SSD}}(t)}{\|\nabla \overline{\operatorname{SSD}}(t)\|},
$$

where the overbar denotes the monthly mean value over the period 1948-2002 and $t$ is expressed in months and corresponds to sampling frequency of the OGCM outputs. The displacement of an isopycnal from its mean location can either be equatorward (Fig. 3a, referred to as situation 1) or poleward (Fig. 3b, referred to as situation 2). The direction of this displacement is given by its projection on the isopycnal currents located on the deeper of the isopycnals $\bar{\sigma}$ and $\sigma$, thus following the path of the isopycnal particles within the thermocline. In situation 1 ,

$$
\mathbf{d l}_{1}(t)=\|\mathbf{d} \mathbf{l}(t)\| \cdot \frac{\overline{\mathbf{u}_{\bar{\sigma}}}(t)}{\left\|\overline{\mathbf{u}_{\bar{\sigma}}}(t)\right\|},
$$

and in situation 2 ,

$$
\mathbf{d l}_{2}(t)=\|\mathbf{d} \mathbf{l}(t)\| \cdot \frac{\mathbf{u}_{\sigma}(t)}{\left\|\mathbf{u}_{\sigma}(t)\right\|}
$$

where $\overline{\mathbf{u}_{\bar{\sigma}}}$ and $\mathbf{u}_{\sigma}$ are the current speeds along the isopycnals $\bar{\sigma}$ and $\sigma$, respectively (Figs. 3a,b). Note that the isopycnal projection of the displacement dl induces 
a)

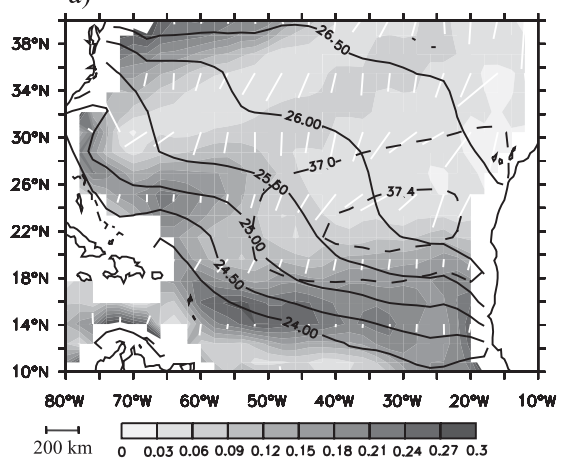

b)

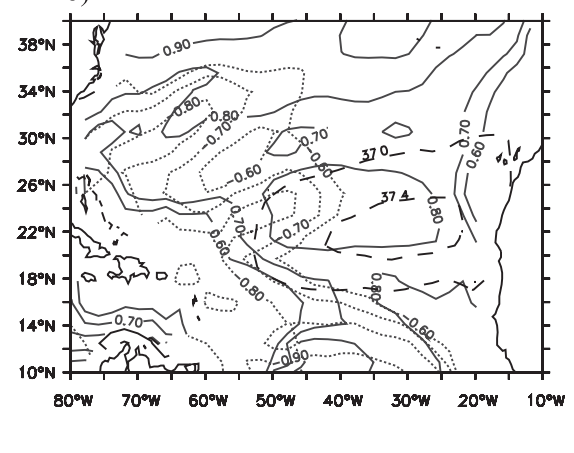

FIG. 4. (a) Amplitude and direction of the mean late-winter (JFM) displacement of the outcropping isopycnals from their mean JFM position over the period of 1948-2002 in the OGCM (respectively, size and orientation of the white segments). The Euclidean norm of the mean JFM sea surface density gradients is shown by the grayscale $\left(\mathrm{kg} \mathrm{m}^{-4}\right)$. The mean JFM position of the outcropping isopycnal surfaces (full) is also shown $\left(\mathrm{kg} \mathrm{m}^{-3}\right)$. (b) Significant correlations between the spatial variabilities of the JFM seasonal averaged amplitude of the displacement $\mathbf{d l}$ and the sea surface temperature anomalies averaged over the period of 19482002 (full contours), significant correlations between the spatial variabilities of the JFM seasonal averaged amplitude of the displacement $\mathbf{d l}$ and the sea surface salinity anomalies over the period of 1948-2002 (dotted contours), and amplitude and direction of the JFM seasonal averaged displacement dl as in (a). The mean JFM maximum sea surface salinity (dashed, psu) is shown in both panels.

errors in regions where the flow is curved that are neglected. This definition of the displacement is more general than that of Nonaka and Sasaki (2007) who considered only a meridional displacement [see appendix B for a comparison between results from Nonaka and Sasaki (2007) and ours].

To understand the generation of spiciness anomalies we develop a model based on a late-winter subduction mechanism (Stommel 1979). During this season and over the period of 1948-2002, the mean amplitude and the direction of the displacement of outcropping isopycnal surfaces from their mean position is shown in Fig. 4a. Simulated averaged displacements of the outcrop lines of isopycnal surfaces reach $400 \mathrm{~km}$ in the SMW region. In the south and the southwestern parts of the region considered here $\left(10^{\circ}-40^{\circ} \mathrm{N}, 80^{\circ}-10^{\circ} \mathrm{W}\right)$, the displacement dl is mainly controlled by winter SSS anomalies, as shown by the significant winter mean correlation coefficient greater than -0.8 between these two fields (Fig. 4b, dashed contours). A freshening of surface waters, for instance, induces a lightening of these waters and a poleward displacement of outcropping isopycnal surfaces $(\mathbf{d l}>0)$, hence the negative correlation. This region is mainly controlled by the ITCZ variability, which induces strong salinity variations as opposed to the SMW region, which is mostly sensitive to temperature variations. In the rest of the domain, the displacement of outcropping isopycnal surfaces is mainly controlled by winter SST anomalies generated in this area, as shown by the significant winter mean correlation coefficient of 0.8 between these two fields (Fig. 4b, full contours). For instance, a warming of surface waters induces a lightening of these waters and a poleward displacement of outcropping isopycnal surfaces $(\mathbf{d l}>0)$, and hence the positive correlation.

\section{b. Definition of spiciness anomalies, SSS anomalies, and SST anomalies in the OGCM}

To relate the displacement dl of the outcropping isopycnal and the surface anomalies to the spiciness anomalies in the permanent thermocline, we first need to define the different anomalies. The spiciness anomalies, the SSS anomalies, and the SST anomalies are defined with respect to a given isopycnal surface $\sigma$. An ISA and an ITA in the thermocline are computed as

$$
\left\{\begin{array}{c}
\operatorname{ISA}_{\sigma(t)}(t)=S_{\sigma(t)}(t)-\overline{S_{\overline{\sigma(t)}}}(t) \\
\operatorname{ITA}_{\sigma(t)}(t)=T_{\sigma(t)}(t)-\overline{T_{\overline{\sigma(t)}}(t)}
\end{array} .\right.
$$

Similarly, an SSS anomaly and an SST anomaly are defined by

$$
\left\{\begin{array}{l}
\operatorname{SSSA}_{\sigma(t)}(t)=\operatorname{SSS}_{\sigma(t)}(t)-\overline{\operatorname{SSS}_{\bar{\sigma}(t)}(t)} \\
\operatorname{SSTA}_{\sigma(t)}(t)=\operatorname{SST}_{\sigma(t)}(t)-\overline{\operatorname{SST}_{\bar{\sigma}(t)}(t)}
\end{array} .\right.
$$

These definitions are valid in both situations 1 and 2 and are illustrated in Fig. 3. 


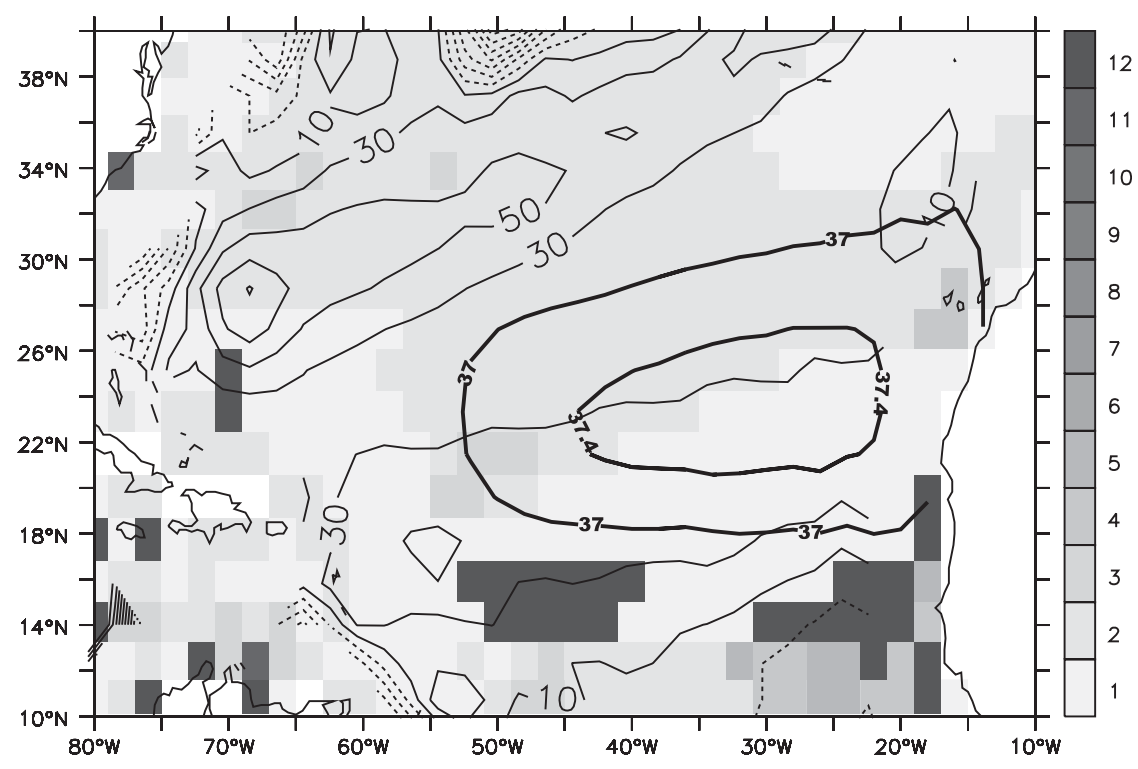

FIG. 5. Month (1-12 for January-December) of maximum monthly mean mixed layer depth (grayscale) over the period of 1948-2002 in the OGCM. The annual mean net ventilation rate is contoured (thin and dashed, contour interval: $20 \mathrm{~m} \mathrm{yr}^{-1}$ ). The mean winter maximum sea surface salinity is highlighted by the isohaline 37 and 37.4 psu (bold).

\section{c. Transfer of the spiciness anomalies from the surface to the permanent thermocline}

We suggest that the transfer of the spiciness anomalies [defined by expressions (3)] from the surface to the permanent thermocline is to first order a quasi-adiabatic detrainment of the signals occurring at the end of winter. The surface spiciness anomalies enter the permanent thermocline and circulate at the current speed by a classical subduction mechanism (Stommel 1979; Luyten et al. 1983). As was pointed out by Marshall et al. (1993), the most efficient subduction region in the North Atlantic subtropical gyre corresponds to the southern SMW region, as shown in Fig. 5, in agreement with Blanke et al. (2002). Subduction on the order of 30 $\mathrm{m} \mathrm{yr}^{-1}$ in the southern SMW region occurs in this simulation during the mixed layer restratification from January to March (Fig. 5), consistent with Marshall et al. (1993) and Lazar et al. (2002). The quasi-adiabatic detrainment of the signals during the subduction season is illustrated by the continuity of the salinity from the surface to the subsurface along the isopycnal surface $\sigma=26 \mathrm{~kg} \mathrm{~m}^{-3}$ in the SMW region (Fig. 6). In the southern SMW region the mean SSS in March and the mean isopycnal salinity on $\sigma=26 \mathrm{~kg} \mathrm{~m}^{-3}$ in April when the mixed layer is becoming shallower have similar amplitudes and the difference is no higher than $0.6 \%$ of the amplitude of the interannual salinity signals. The amplitude of the subducted spiciness anomalies varies during their journey in the thermocline. The persistence of the anomalies depends on the volume of subducted waters and on the range of outcropping isopycnal surfaces in the subduction region. If the volume of waters subducted is large and the range of outcropping isopycnal surfaces is small, then the spiciness anomalies might be persistent when they circulate in the thermocline. The volume of subducted waters depends on the late-winter anomalous MLD in the subduction region. We assume that the OGCM is able to reproduce the anomalous MLD, and thus the volume of subducted spiciness anomalies. The modulation of the characteristics of the subducted salinity signals resulting from the vertical fluctuations of the MLD during the detrainment season is thus neglected to a first-order approximation.

\section{d. Analytical expressions of the spiciness anomalies in the thermocline}

To understand how an $\mathrm{SSSA}_{\sigma}$ (respectively, an SSTA ) is transferred to the permanent thermocline into an ISA $_{\sigma}$ (respectively, an ITA ${ }_{\sigma}$ ), we must first relate the surface signals $\left(\mathrm{SSS}_{\sigma}\right.$ and $\left.\mathrm{SST}_{\sigma}\right)$ to the signals in the permanent thermocline $\left(S_{\sigma}\right.$ and $\left.T_{\sigma}\right)$. Then, we must relate the mean surface signals $\left(\overline{\mathrm{SSS}_{\bar{\sigma}}}\right.$ and $\left.\overline{\mathrm{SST}_{\bar{\sigma}}}\right)$ to the mean signals in the permanent thermocline $\left(\overline{S_{\bar{\sigma}}}\right.$ and $\left.\overline{T_{\bar{\sigma}}}\right)$. Because the properties of surface waters are not affected during their transfer into the thermocline, either the subsurface salinity or temperature along a given isopycnal surface $\sigma\left(S_{\sigma}\right.$ and $\left.T_{\sigma}\right)$ can be estimated by considering the SSS and the SST along the outcrop line 


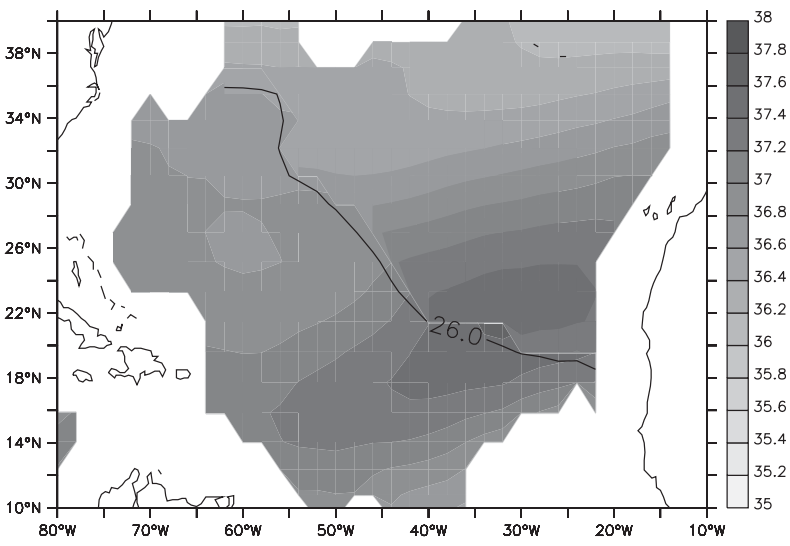

FIG. 6. Mean SSS north of the outcropping isopycnal $\sigma=26$ $\mathrm{kg} \mathrm{m}^{-3}$ in March and mean salinity (psu) on the isopycnal $\sigma=26$ $\mathrm{kg} \mathrm{m}^{-3}$ south of the outcrop line in April over the period of 1948-2002 in the OGCM. The regions of obduction have been filtered out using the annual net ventilation rate shown in Fig. 5.

of $\sigma\left(\mathrm{SSS}_{\sigma}\right.$ and $\left.\mathrm{SST}_{\sigma}\right)$ and the amplitude and direction of the displacement of this outcrop line $\left(\mathbf{d l}_{1}\right.$ or $\left.\mathbf{d l}_{2}\right)$ in a varying field of horizontal gradients of SSS and SST. In the subtropical North Atlantic Ocean, the vertical profile of the simulated spiciness anomalies exhibit no increase over very short time periods on isopycnal surfaces that have not outcropped during the winter season (not shown). In this region, we suggest that classical subduction dominates and we can therefore assume that the isopycnal salinity and temperature are not altered by subsurface processes. The analytical prognostic expressions for the subsurface isopycnal salinity and temperature are very similar in situations 1 and 2, and we only give them for the situation 2 (and rename $\mathbf{d l}_{\mathbf{2}}$ into $\mathbf{d l}$ ),

$$
\left\{\begin{array}{c}
S_{\sigma(t)}(t)=\operatorname{SSS}_{\bar{\sigma}(t)}(t-1)+\mathbf{d l}(t-1) \cdot \nabla \operatorname{SSS}(t-1) \\
T_{\sigma(t)}(t)=\operatorname{SST}_{\bar{\sigma}(t)}(t-1)+\mathbf{d l}(t-1) \cdot \nabla \operatorname{SST}(t-1)
\end{array}\right.
$$

where the 1-month delay is the best estimated time needed for the surface signal along the monthly outcropping isopycnal surface to reach the position, which is right under the outcrop line of the monthly mean isopycnal surface (not shown, see Fig. 3b). This delay varies from 1 to 3 months from year to year, and we therefore expect the analytical expressions (5) to lack realism on interannual time scales. The analytical prognostic expressions for the mean subsurface isopycnal salinity and temperature (Fig. 3) are given by

$$
\left\{\begin{array}{l}
\overline{S_{\bar{\sigma}(t)}}(t)=\overline{\operatorname{SSS}_{\bar{\sigma}(t)}}(t) \\
\overline{T_{\bar{\sigma}(t)}}(t)=\overline{\operatorname{SST}_{\bar{\sigma}(t)}}(t)
\end{array} .\right.
$$

These expressions give a forecasting of the mean subsurface salinity and temperature signals based on only the mean surface salinity and temperature, which are known quantities.

The resulting analytical prognostic expressions of the ISA $_{\sigma}$ and ITA $_{\sigma}$ are obtained by computing the difference between (5) and (6) so that

$$
\left\{\begin{array}{rl}
\operatorname{ISA}_{\sigma(t)}(t) & =\operatorname{SSSA}_{\bar{\sigma}(t)}(t-1)+\mathbf{d l}(t-1) \cdot \nabla \operatorname{SSS}(t-1) \\
\operatorname{ITA}_{\sigma(t)}(t) & =\operatorname{SSTA}_{\bar{\sigma}(t)}(t-1)+\mathbf{d l}(t-1) \cdot \nabla \operatorname{VST}(t-1)
\end{array} .\right.
$$

The definitions of either a subducted ISA or ITA according to expressions (7) only depend on parameters that can be obtained from in situ and satellite data and from climatologies of SSS, SST, and currents if the spatial and temporal samplings are dense enough in the formation region of the spiciness anomalies.

\section{Comparison between the analytical and the OGCM spiciness anomalies}

\section{a. Spatial distribution and temporal variability of the analytical spiciness anomalies}

The analytical spiciness anomalies given by the expressions (7) are compared against the OGCM ones defined by Eq. (3). The terms on the right-hand side of Eq. (7) are computed using the OGCM instead of observations in the thermocline, which are scarce on decadal time scales. Only spiciness anomalies under the base of the deepest winter mixed layer are considered during the month following the month of maximum MLD because they might ventilate the subtropical gyre. Only subduction regions are considered and obduction regions (the equatorial region south of $14^{\circ} \mathrm{N}$ and the Gulf Stream region) are filtered out using the simulated annual mean ventilation rate (Fig. 5).

To illustrate the surface generation of the spiciness anomalies defined by Eq. (7), the different terms in the first equation are shown in 1976 when a strong positive anomaly close to 0.3 psu is subducted in the thermocline in the western SMW region (Fig. 7). The subduction period in 1976 is characterized by a feature that occurs in particular between $22^{\circ}-26^{\circ} \mathrm{N}$ and $42^{\circ}-35^{\circ} \mathrm{W}$ (highlighted by the box on each panel of Fig. 7). During this period the SSS anomalies and the associated subducted ISAs are of opposite signs. In March 1976, the surface waters in this area are freshened by about 0.4 psu and cooled by about $2.5^{\circ} \mathrm{C}$ (Fig. 7a). This SST anomaly controls the southward displacement of the outcropping isopycnal surfaces, which is on the order of $1000 \mathrm{~km}$ (Fig. 7b). The scalar product of this displacement by the gradient of SSS [second term on the right-hand side of the first Eq. (7)] is on the order of 0.7 psu (Fig. 7c) and the associated analytical ISAs are on the order of 0.3 psu (Fig. 7d). 
a) SSSA and SSTA in March 1976

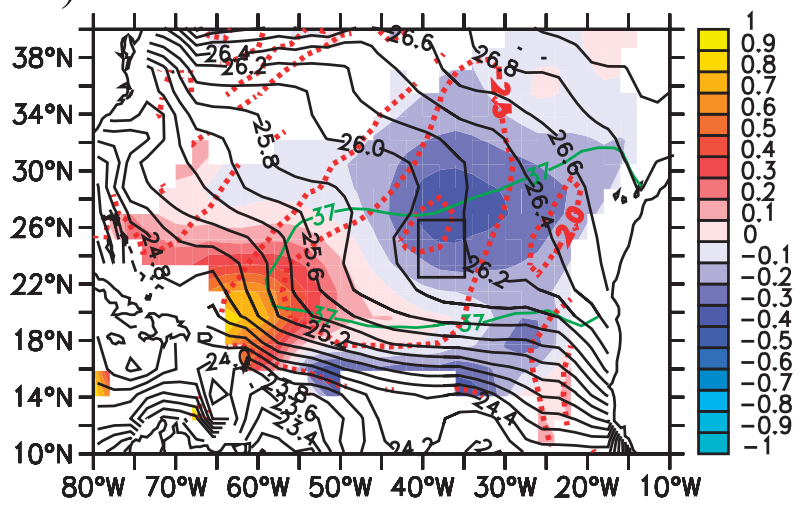

b) Migration $(d l)$ in March 1976

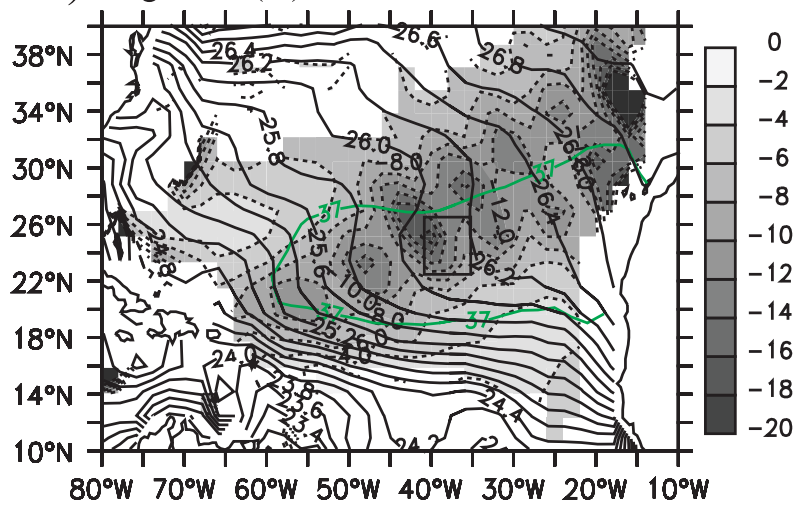

c) $d l \cdot \nabla S S S$ in March 1976

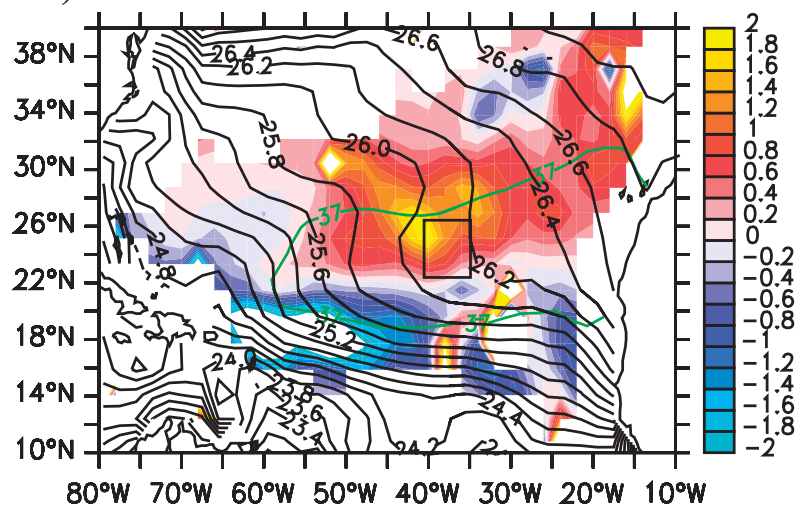

d) Analytical ISA in April 1976

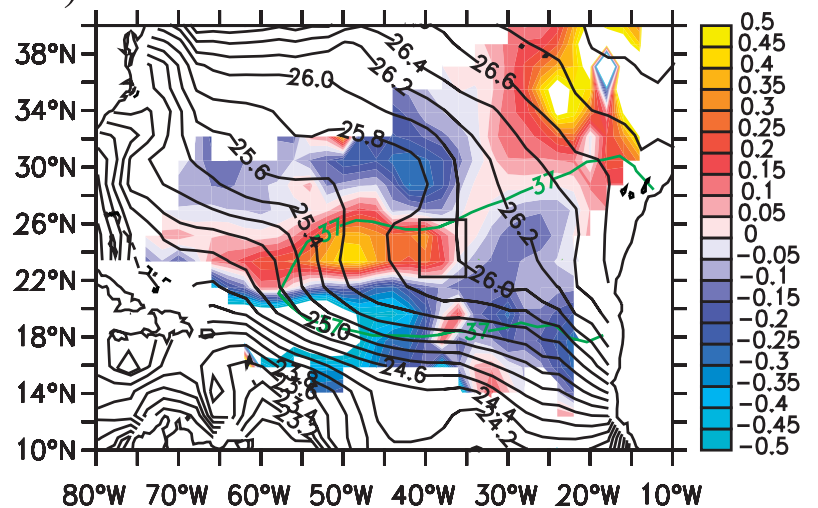

e) Simulated ISA in April 1976

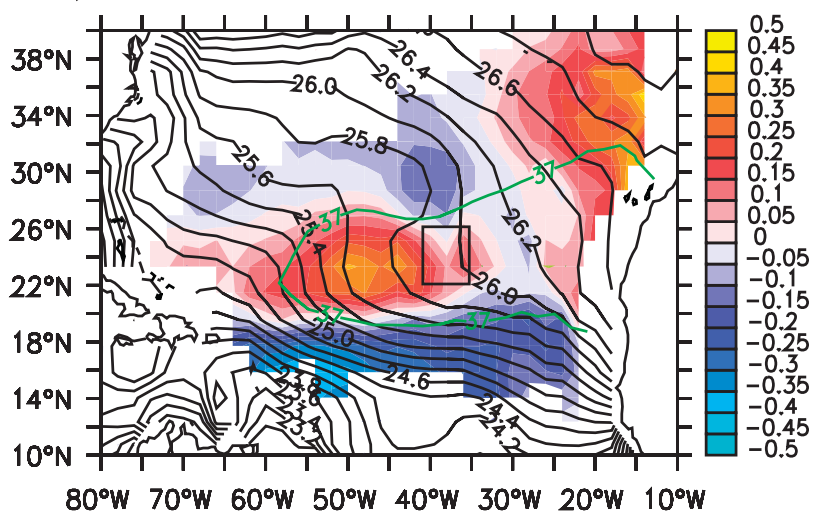

FIG. 7. Decomposition of the terms in Eq. (7) in March and April 1976 as indicated on top of each panel in the OGCM. (a) Sea surface salinity anomalies (psu) and sea surface temperature anomalies $\left({ }^{\circ} \mathrm{C}\right.$, red contours). (b) Amplitude of the displacement dl in degrees of latitude. (c) Scalar product of the displacement dl and the sea surface salinity gradients. (d) Subducted isopycnal salinity anomalies given by the analytical expression (7) at the base of the mixed layer (psu). (e) Same as in (d), but for the simulated anomalies using the OGCM. In all panels, the outcropping isopycnal surfaces are contoured in black, the salinity maximum water region is highlighted by the isohaline $37 \mathrm{psu}$ contoured in green, the rectangle highlights the region of $22^{\circ}-26^{\circ} \mathrm{N}, 42^{\circ}-35^{\circ} \mathrm{W}$, discussed in the text, and the obduction regions are filtered out using the annual mean ventilation rate shown on Fig. 5. 
This amplitude of the analytical ISAs is consistent with that of the corresponding simulated ISAs (on the order of 0.3 psu; Fig. 7e). In the subtropical gyre, the amplitude of the subducted ISAs given by Eq. (7) is overestimated by about $0.15 \mathrm{psu}$ in absolute value compared to that of the OGCM ones given by (3) (cf. Figs. 7d,e). The discrepancy in amplitude between the analytical and the OGCM ISAs northeast of $30^{\circ} \mathrm{N}, 30^{\circ} \mathrm{W}$ is most likely explained by the displacement of the outcropping isopycnal, which is too large for the linear expression (7) to be valid (Fig. 4a). Southwest of $22^{\circ} \mathrm{N}$, $45^{\circ} \mathrm{W}$, the strong horizontal gradients of SSS resulting from the ITCZ variability lead to errors in the second term on the right-hand side of expression (7), which are responsible for the discrepancy in amplitude between the analytical and the simulated ISAs. Despite these biases in amplitude the analytical model captures the spatial distribution of the subducted ISAs in 1976. Negative analytical ISAs south of $22^{\circ} \mathrm{N}$ are forecasted (Fig. 7d), which agrees with the negative ISAs south of $20^{\circ} \mathrm{N}$ simulated using the OGCM (Fig. 7e). Similarly, positive analytical ISAs are forecasted between $22^{\circ}$ and $28^{\circ} \mathrm{N}$ and northeast of $28^{\circ} \mathrm{N}, 35^{\circ} \mathrm{W}$ (Fig. 7d), in agreement with the positive OGCM ISAs located between $20^{\circ}$ and $28^{\circ} \mathrm{N}$ and northeast of $28^{\circ} \mathrm{N}, 35^{\circ} \mathrm{W}$ (Fig. 7e). The negative ISAs forecasted by expression (7) northwest of $28^{\circ} \mathrm{N}, 35^{\circ} \mathrm{W}$ are also simulated by the OGCM in the same region.

In 1976, the late-winter SSS anomalies act to damp the amplitude of the subducted ISAs in this region, and the relationship between surface and subsurface isopycnal salinity anomalies are controlled by the second term on the right-hand side of the first Eq. (7) related to the displacement of outcropping isopycnal surfaces. In 1976, this relationship does not occur everywhere in the North Atlantic subtropical gyre. South of $18^{\circ} \mathrm{N}$ and east of $55^{\circ} \mathrm{W}$, for example, the two terms on the right-hand side of expression (7) are negative (SSS anomaly on the order of $-0.2 \mathrm{psu}$ and scalar product on the order of $-1.5 \mathrm{psu}$ ) and the resulting subducted ISA is negative as well with a stronger amplitude than that of the SSS anomaly in this region. Hence, the amplitude of the subducted ISAs is either amplified or damped compared to the one of the surface anomalies and their sign is either the same as or opposite to the one of the surface anomalies, as discussed in Fig. 2.

To compare the analytical ISAs and the OGCM ones over the period of 1948-2002, their respective first and second empirical orthogonal functions (EOFs) and associated principal components (PCs) are shown in Fig. 8 . Given the uncertainties associated with the analytical expressions of the spiciness anomalies on interannual time scales, the interannual variability of the SSS anomalies, the SST anomalies, and the analytical and OGCM spiciness anomalies is filtered out using a 3-yr binomial smoother. The first EOFs of the analytical and the OGCM ISAs represent, respectively, $34 \%$ and $21.3 \%$ of the variance of the subtropical gyre (Figs. 8a,b). They both highlight a dipole structure between the northeastern and the southwestern subtropical gyre. In the northeastern subtropical gyre the strongest amplitude of the analytical and the OGCM ISAs occurs near the Canary Islands (on the order of 0.07 and 0.13 psu, respectively). In the southwestern subtropical gyre the strongest amplitude of the OGCM ISAs occurs east and southeast of the Caribbean Islands (between $10^{\circ}-22^{\circ} \mathrm{N}$ and $65^{\circ}-40^{\circ} \mathrm{W}$, on the order of $0.03 \mathrm{psu}$ ), and it occurs northeast of the Dominican Republic in the first EOF of the analytical ISAs (between $18^{\circ}-26^{\circ} \mathrm{N}$ and $60^{\circ}-40^{\circ} \mathrm{W}$, on the order of $0.05 \mathrm{psu}$ ). The analytical model reproduces the spatial distribution and the amplitude of the first EOF of the simulated ISAs. It also captures their temporal variability as shown by the PCs associated to the first EOFs of the analytical and simulated ISAs. They are significantly correlated with a coefficient of 0.83 and highlight a strong decadal variability, which is in agreement with the results from LLR.

The second EOFs of the analytical and the OGCM ISAs represent, respectively, $16.5 \%$ and $15.1 \%$ of the variance of the subtropical gyre. They both highlight a dipole structure between the central subtropical gyre (between $18^{\circ}-30^{\circ} \mathrm{N}$ and $55^{\circ}-25^{\circ} \mathrm{W}$ ) and the southwestern subtropical gyre (between $20^{\circ}-30^{\circ} \mathrm{N}$ and $55^{\circ}-25^{\circ} \mathrm{W}$ ). The amplitude of the maxima in the analytical model is overestimated by about 0.04 psu. The analytical model is able to reproduce the spatial distribution of the second EOF of the simulated ISAs. It also captures their temporal variability because the PCs associated to the second EOFs of the analytical and the simulated ISAs are significantly correlated with a coefficient of 0.73 . The first two EOF modes are sufficient to explain half of the low-frequency variability in the OGCM: the first mode is maximum in the northeastern subtropics and the second is over the central basin.

\section{b. Discussion}

How are the main patterns of spiciness anomalies in the permanent thermocline related to the SSS anomalies and the SST anomalies over the period of 19482002? To relate the first and the second EOFs of the spiciness anomalies in the thermocline with patterns of SSS anomalies and SST anomalies, we rewrite the displacement dl defined by expression (2) using Eq. (1). The expression for dl becomes

$$
\|\mathbf{d l}(t)\|=-\frac{\beta \operatorname{SSSA}_{\bar{\sigma}(t)}(t)-\alpha \operatorname{SSTA}_{\bar{\sigma}(t)}(t)}{\beta \partial_{l} \overline{\mathrm{SSS}}-\alpha \partial_{l} \overline{\mathrm{SST}}} .
$$




\section{a) Simulated isopycnal salinity anomalies}

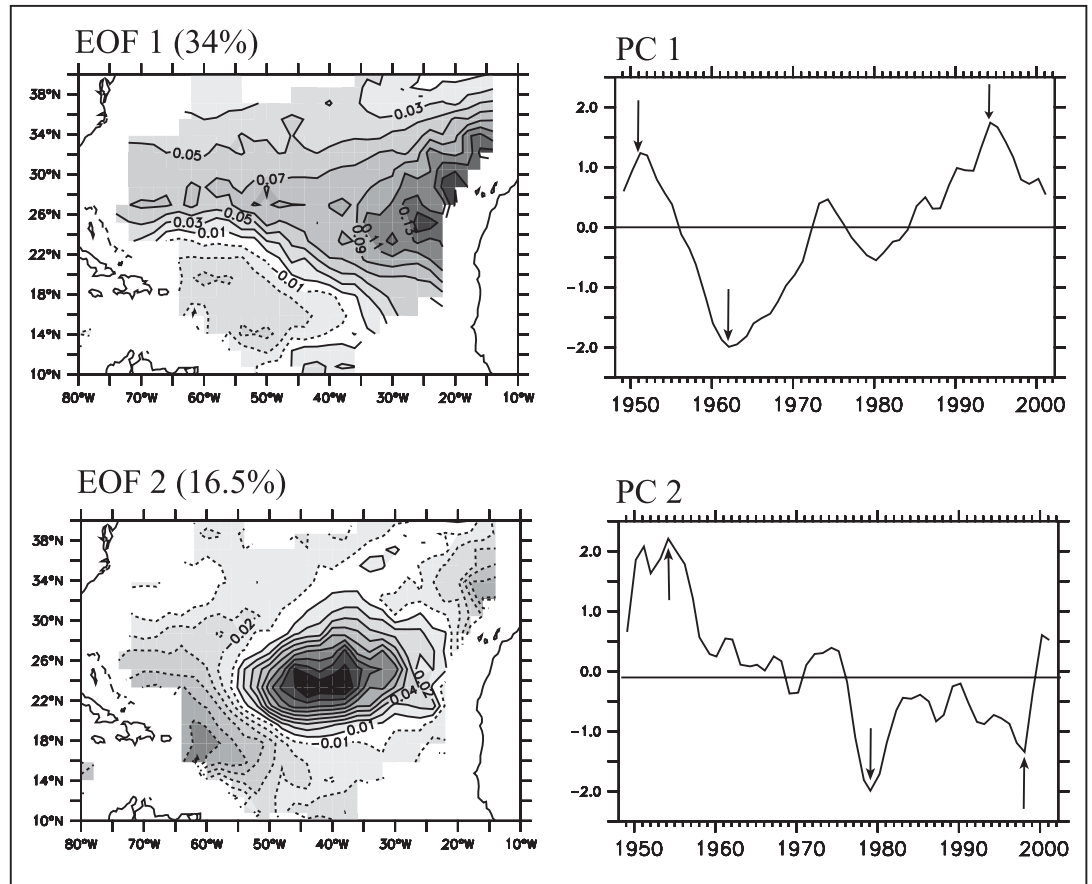

b) Analytical isopycnal salinity anomalies

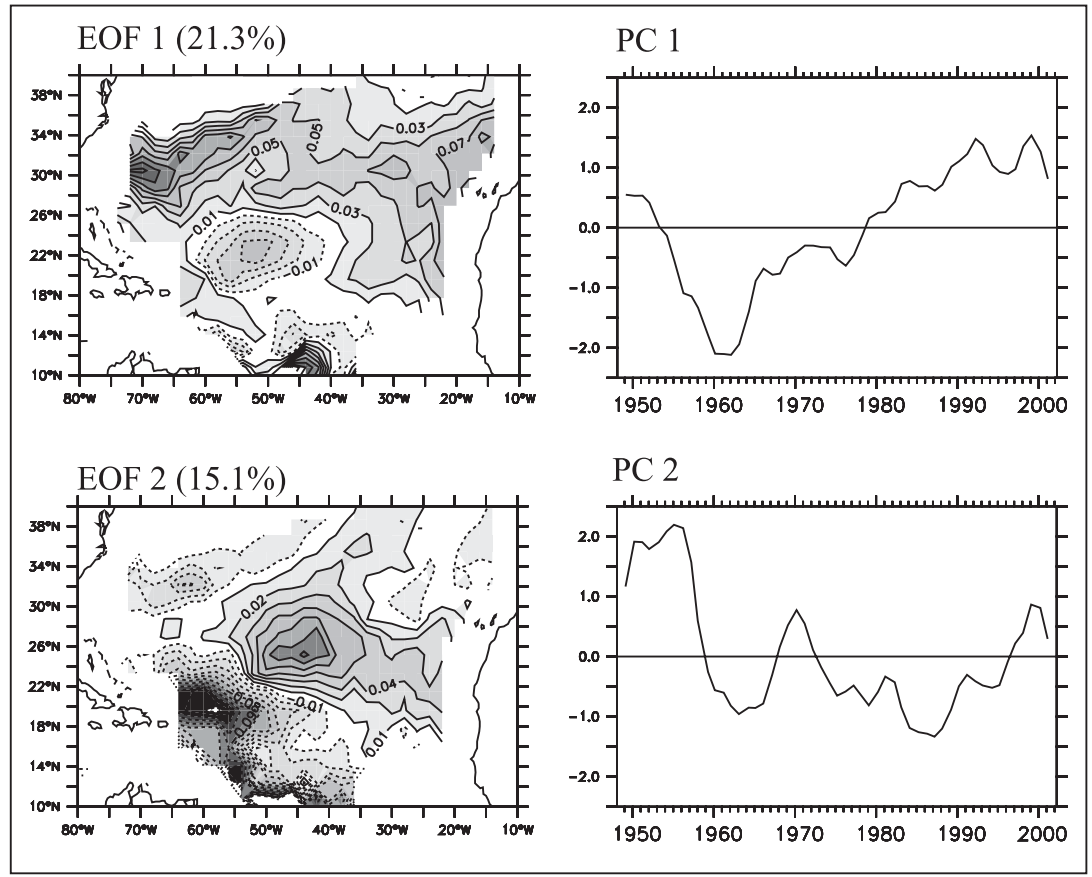

FIG. 8. First and second EOFs and associated PCs of the (a) simulated and (b) analytical isopycnal salinity anomalies at the mixed layer base during the month following that of maximum MLD (psu). The interannual variability of the SSS anomalies, the SST anomalies, and the analytical and OGCM spiciness anomalies is filtered out using a 3-yr binomial smoother. The percentage of represented variance is given in parentheses. The principal components are unitless. The arrows in (a) indicate the years chosen to build the composite discussed in the text. The regions of obduction have been filtered out using the annual net ventilation rate shown in Fig. 5. 


\section{a) $R^{*}$}

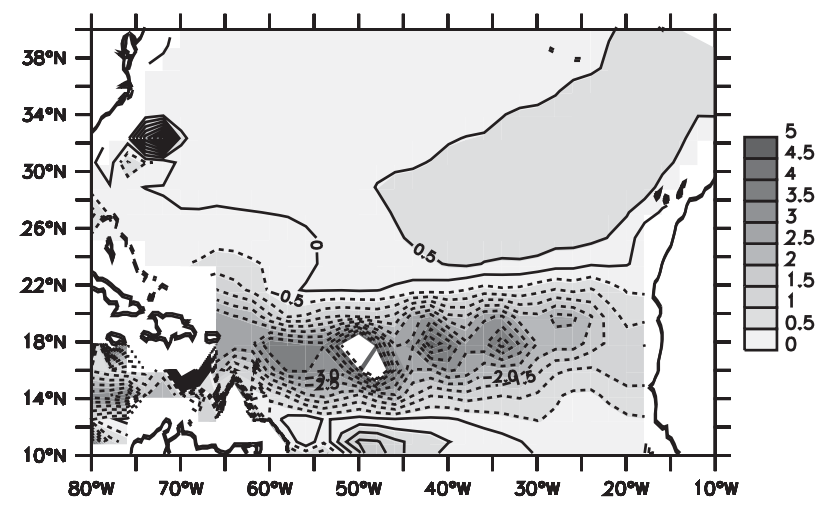

b) $R_{S, S}$

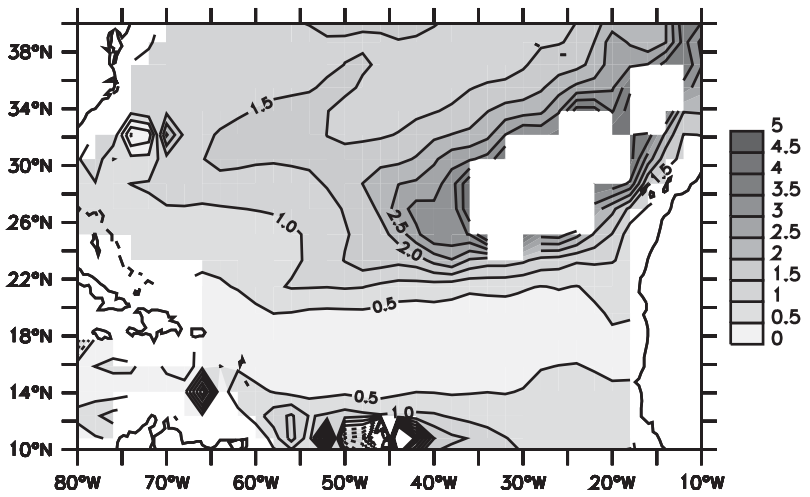

c) $R_{S, T}$

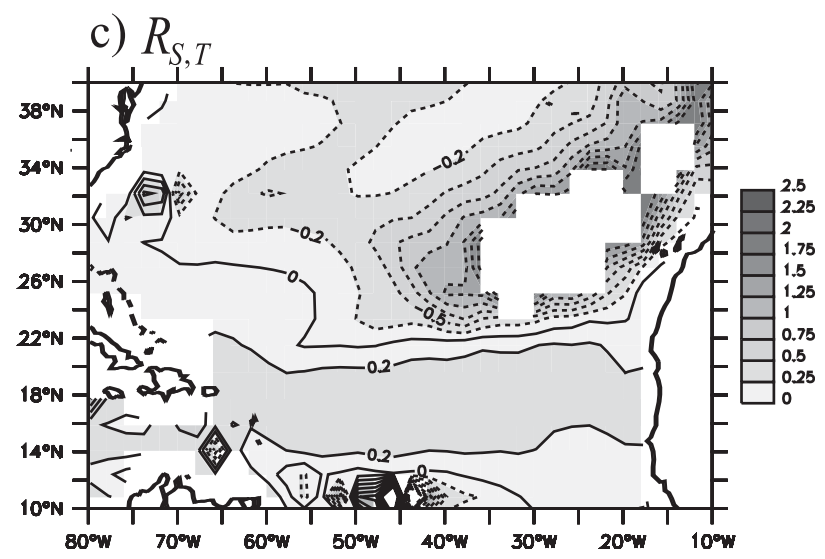

FIG. 9. (a) Annual mean density ratio $R^{*}$ (unitless). (b) Annual mean coefficient $R_{S, S}$ (unitless). (c) Annual mean coefficient $R_{S, T}$ (unitless). Regions where $R^{*}$ is between 0.8 and 1.2 are masked in (b) and (c). See the text.

We introduce the density ratio $R^{*}$ defined by $R^{*}=\left(\beta \partial_{l} \overline{\mathrm{SSS}}\right) /\left(\alpha \partial_{l} \overline{\mathrm{SST}}\right)$, where the gradients are considered in the same direction as dl. The inverse of $R^{*}$ is usually considered in thermohaline variability studies in the mixed layer (e.g., Rudnick and Ferrari 1999; Rudnick and Martin 2002, among others), but it is undefined in the SMW region where the horizontal gradients of SSS vanish. When replacing the expression of the $\mathbf{d l}$ in Eqs. (7), the ISAs and ITAs become

$$
\left\{\begin{array}{l}
\operatorname{ISA}_{\sigma(t)}(t)=R_{S, S} \cdot \operatorname{SSSA}_{\bar{\sigma}(t)}(t)+R_{S, T} \cdot \operatorname{SSTA}_{\bar{\sigma}(t)}(t) \\
\operatorname{ITA}_{\sigma(t)}(t)=R_{T, S} \cdot \operatorname{SSSA}_{\bar{\sigma}(t)}(t)+R_{T, T} \cdot \operatorname{SSTA}_{\bar{\sigma}(t)}(t)
\end{array},\right.
$$

where $R_{S, S}=1 /\left(1-R^{*}\right), R_{S, T}=\alpha R^{*} /\left[\beta\left(R^{*}-1\right)\right], R_{T, S}=$ $\beta /\left[\alpha\left(1-R^{*}\right)\right]$, and $R_{T, T}=R^{*} /\left(R^{*}-1\right)$.

Note that $\operatorname{ITA}_{\sigma(t)}(t)=\left(\beta . \alpha^{-1}\right) \operatorname{ISA}_{\sigma(t)}(t)$ as expected. The expressions (8) allow a complete discussion of the characteristics of the spiciness anomalies in the permanent thermocline as a function of SSS and SST anomalies, and $R^{*}$, away from density-compensated regions where $R^{*}=1$. The annual mean patterns of $R^{*}$,
$R_{S, S}$, and $R_{S, T}$ are shown in Fig. 9. Surface waters become warmer and fresher as they approach the ITCZ region, hence the strong negative value of $R^{*}$ in this region (on the order of -4 ; Fig. 9a). Similarly, waters become colder and fresher poleward as indicated by the positive value of $R^{*}$. Density-compensated regions are located in the northeast of the subtropical gyre, between $26^{\circ}-30^{\circ} \mathrm{N}$ and $35^{\circ}-20^{\circ} \mathrm{W}$.

Using expression (8), different regimes of transformation from surface anomalies into spiciness anomalies in the thermocline are highlighted by Figs. 9b,c. Between $14^{\circ}$ and $22^{\circ} \mathrm{N}$, the ISAs in the permanent thermocline are a combination of reduced SSS anomalies and reduced SST anomalies as indicated by the weakly positive coefficients $R_{S, S}$ and $R_{S, T}$ in this region (Figs. $9 \mathrm{~b}, \mathrm{c})$. In the northwestern part of the subtropical gyre, north of $28^{\circ} \mathrm{N}$ between $80^{\circ}$ and $60^{\circ} \mathrm{W}$, the ISAs in the permanent thermocline are a combination of amplified SSS anomalies (as shown by the positive value of $R_{S, S}$ greater than 1) and reduced and opposite SST anomalies (as shown by the weakly negative value of $\left.R_{S, T}\right)$. In the SMW region, the ISAs in the permanent 
thermocline are a combination of amplified SSS anomalies and amplified and opposite SST anomalies. A similar discussion can be done for the coefficients $R_{S, T}$ and $R_{T, T}$ associated to the analytical ITAs in the thermocline.

To discuss the late-winter surface conditions that have generated the pattern of the OGCM ISAs given by their first EOF (Fig. 8a), composites of the SSS anomalies, the SST anomalies, and the OGCM ISAs are constructed using 3 years $(1951,1962$, and 1994, as indicated by the arrows on Fig. 8a) when the pattern of the OGCM ISAs most resembles that of their first EOF over the period of 1948-2002. The pattern computed by applying the first equation in (8) to the composites of the SSS anomalies (Fig. 10a) and SST anomalies (Fig. $10 \mathrm{~b}$ ) is compared against the pattern of the composite of the OGCM ISAs (Fig. 10e). The associated reconstructed ISAs shown on Fig. 10e are thus the sum of the first term on the right-hand side of (8) (Fig. 10c) and the second term on the right-hand side of (8) (Fig. 10d).

The spatial distribution of the resulting reconstructed ISAs (Fig. 10f) is very similar to that of the composite OGCM ISAs featuring positive anomalies in the northeastern part of the subtropical gyre and negative anomalies in the southwestern part of the gyre. The maximum amplitude of the OGCM ISAs located along the African coast (on the order of $0.2 \mathrm{psu}$ ) is shifted northward in the analytical reconstruction. The amplitude of the reconstructed ISAs is very similar to the one of the composite OGCM ISAs, except in the region where $R^{*}$ is close to 1 and where the reconstruction is not valid, causing the maximum amplitude to have an anomalous position and an anomalous amplitude (on the order of $0.3 \mathrm{psu}$ ). The discrepancies in amplitude and in the location of the maxima are also likely related to the nonlinearities of the density, which are neglected in this analytical model. The pattern of the reconstructed analytical ISAs is mainly controlled by that of the term associated to the SSS anomalies (Fig. 10c). However, the term associated with the SST anomalies (Fig. 10d) decreases the amplitude of the reconstructed ISAs northwest of $26^{\circ} \mathrm{N}, 65^{\circ} \mathrm{W}$ and southeast of $20^{\circ} \mathrm{N}, 50^{\circ} \mathrm{W}$. Therefore, SSS and SST anomalies have competing effects on the characteristics of the ISAs in the North Atlantic subtropical gyre, depending on the density ratio $R^{*}$.

Composites of the SSS anomalies, the SST anomalies, and the OGCM ISAs are then constructed using 3 years $(1954,1979$, and 1999 as indicated by the arrows on Fig. 8a) when the pattern of the OGCM ISAs most resembles that of their second EOF (Fig. 11). The reconstructed analytical ISAs (Fig. 11f) have a similar spatial distribution to that of the OGCM ISAs (Fig. 11e), with strong positive anomalies in the center of the subtropical gyre and negative anomalies elsewhere. However, the maximum amplitude of the reconstructed ISAs (on the order of $0.3 \mathrm{psu}$ ) is located at $26^{\circ} \mathrm{N}$, between $40^{\circ}$ and $30^{\circ} \mathrm{W}$, northeastward of the maximum amplitude of the OGCM ISAs $\left(24^{\circ} \mathrm{N}, 40^{\circ} \mathrm{W}\right.$, on the order of $0.2 \mathrm{psu}$ ). This upstream shift in the location of the maximum suggests a misrepresentation of the timing of subduction, likely related to the definition of the direction of the outcropping isopycnal displacement. Although the term associated with the SSS anomalies (Fig. 11c) is mainly controlling the characteristics of the reconstructed ISAs, the term associated with the SST anomalies (Fig. 11d) contributes to the negative sign of the reconstructed analytical ISAs south of $20^{\circ} \mathrm{N}$, between $50^{\circ}$ and $40^{\circ} \mathrm{W}$, and contributes to the weakly positive reconstructed ISAs north of $32^{\circ} \mathrm{N}$, between $40^{\circ}$ and $25^{\circ} \mathrm{W}$.

In both reconstructions of the ISAs in the permanent thermocline (Figs. 10e and 11e), the pattern of the resulting analytical ISAs is very similar to that of the latewinter SSS anomalies (cf. Figs. 10a,e and Figs. 11a,e). Their variabilities are also similar as shown by significant correlation coefficient of 0.84 between the PC associated with the first EOF of the interannual OGCM ISAs (Fig. 8a) and the PC of the first EOF of the laterwinter SSS anomalies (not shown). However, it is noteworthy that warm and salty spiciness anomalies (Fig. 10e) arising between $22^{\circ}$ and $30^{\circ} \mathrm{N}$ during 3 typical years of the first EOF of the OGCM ISAs are set by cool SST anomalies (Fig. 10b) during the subduction season. Similarly, warm and salty spiciness anomalies located in the central subtropical gyre between $18^{\circ}$ and $28^{\circ} \mathrm{N}$ (Fig. 11e) during 3 typical years of the second EOF of the OGCM ISAs are set by cool SST anomalies (Fig. 11b) during the subduction season.

\section{Conclusions}

The generation mechanism of spiciness anomalies has been investigated using an analytical model based on the late-winter subduction of surface salinity and temperature anomalies along isopycnal surfaces. Our analytical model depends on the surface temperature and salinity anomalies, the surface density ratio, and the mean thermocline currents. The analytical outputs have been compared to those of a global run of the OGCM OPA over the period from 1948 to 2002. In the analytical model, the first two EOF modes of the spiciness anomalies are sufficient to explain half of the low-frequency variability in the OGCM. The analytical model reproduces the spatial pattern, amplitude, and sign of these 


\section{a) SSSA (composite)}
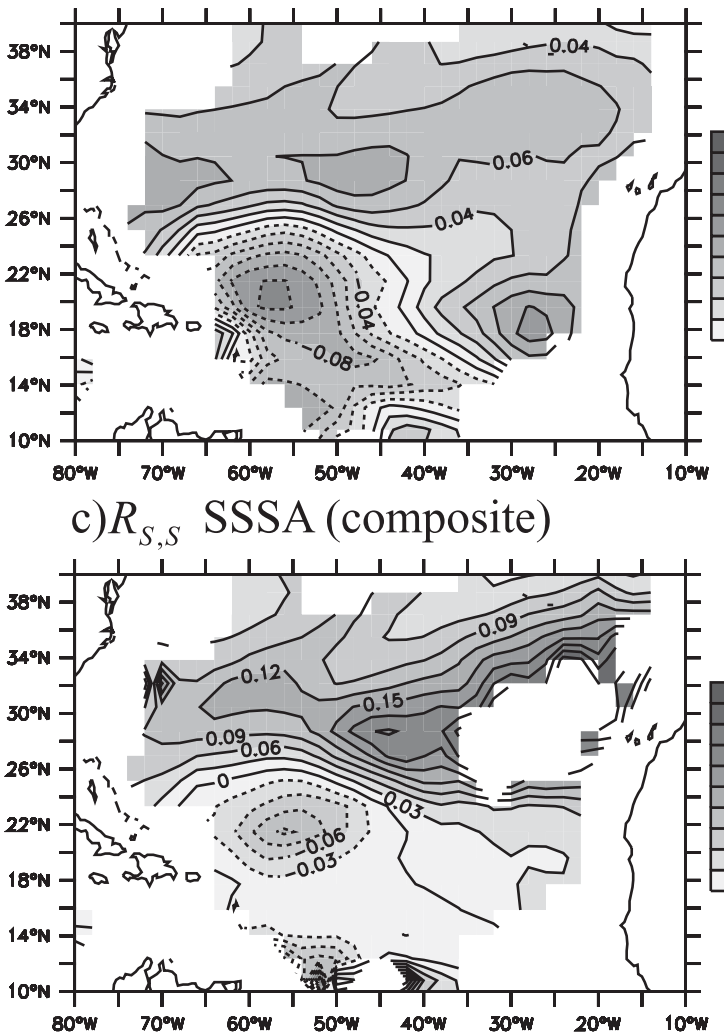

e) OGCM ISA (composite)

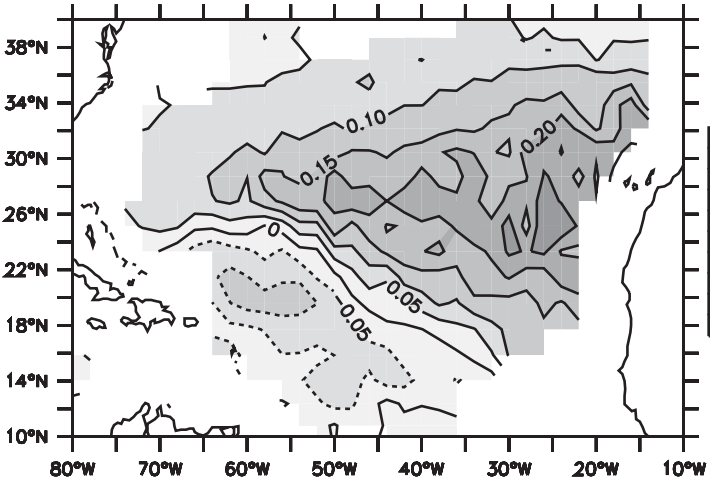

b) SSTA (composite)

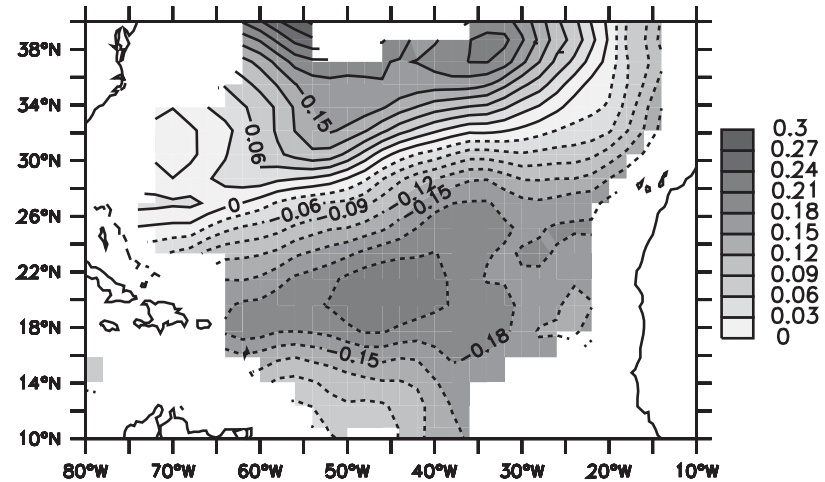

d) $R_{S, T}$ SSTA (composite)

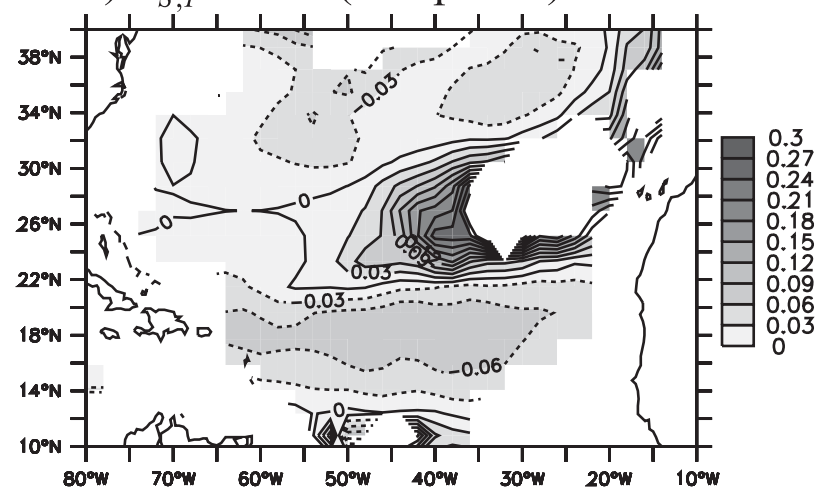

f) Reconstructed ISA (composite)

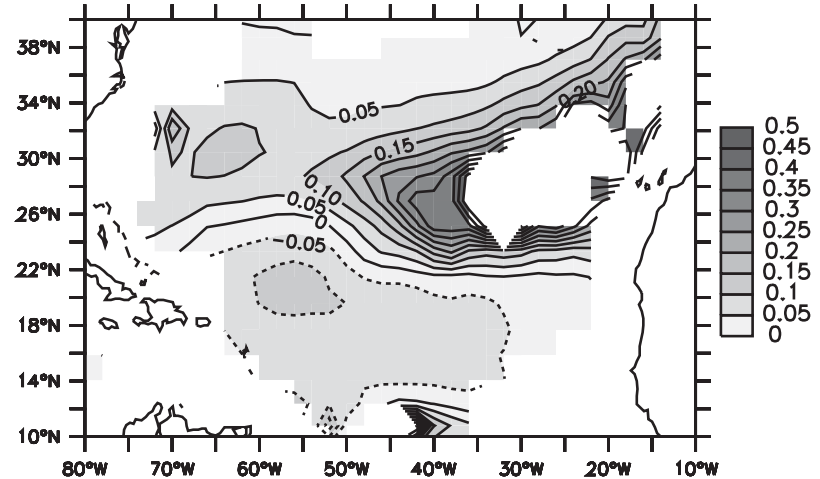

FIG. 10. (a) Composite of the SSS anomalies constructed with the 3 yr highlighted by the arrows on the first PC of the OGCM spiciness anomalies shown in Fig. 8 (psu). (b) Composite of the SST anomalies constructed as in $(\mathrm{a})\left({ }^{\circ} \mathrm{C}\right)$. (c) First term on the right-hand side of expression (8) applied to the composite of the SSS anomalies in (a). (d) Second term on the right-hand side of expression (8) applied to the composite of the SST anomalies in (b). (e) Composite of the isopycnal salinity anomalies in the OGCM; it most resembles the first EOF of the OGCM isopycnal salinity anomalies (psu). (d) Isopycnal salinity anomalies reconstructed from (c) and (d) (psu). Regions where $R^{*}$ is between 0.8 and 1.2 are masked. The regions of obduction have been filtered out using the annual net ventilation rate shown on Fig. 5.

two modes well. The analytical model clarifies and quantifies the mechanism by which surface temperature and salinity anomalies are modulated by density ratios to produce different isopycnal temperature and salinity anomalies. The analytical model has good skills at repro- ducing the decadal variability of the OGCM spiciness anomalies in the permanent thermocline. It is therefore an interesting tool to understand and forecast the ventilation of the North Atlantic subtropical gyre at this time scale. 
a) SSSA (composite)

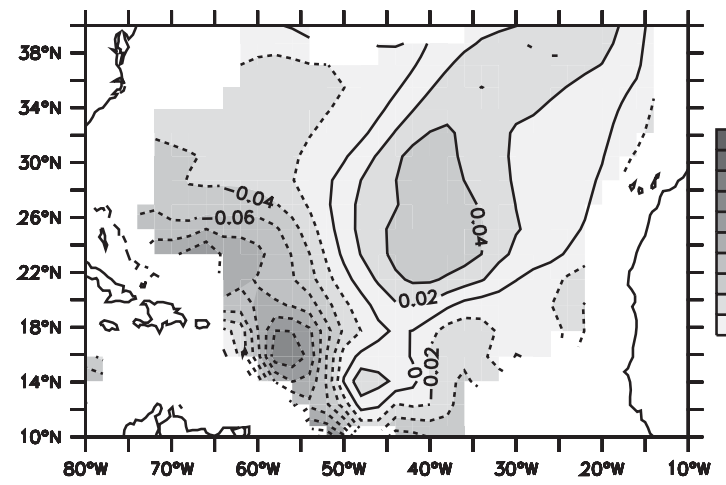

c) $R_{S, S} \mathrm{SSSA}$ (composite)

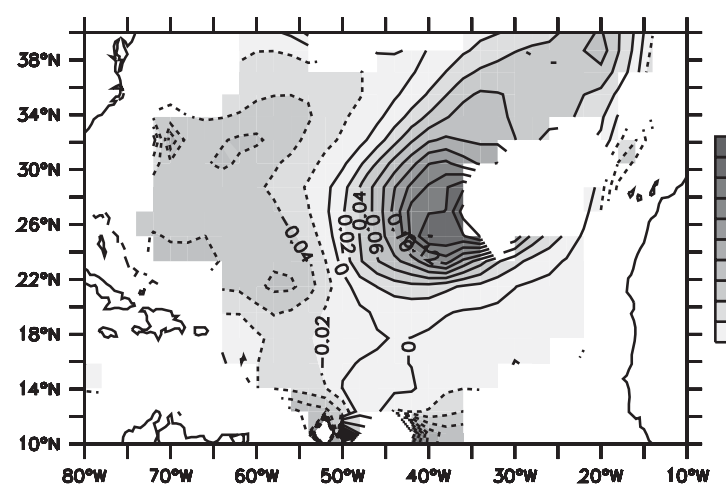

e) OGCM ISA (composite)

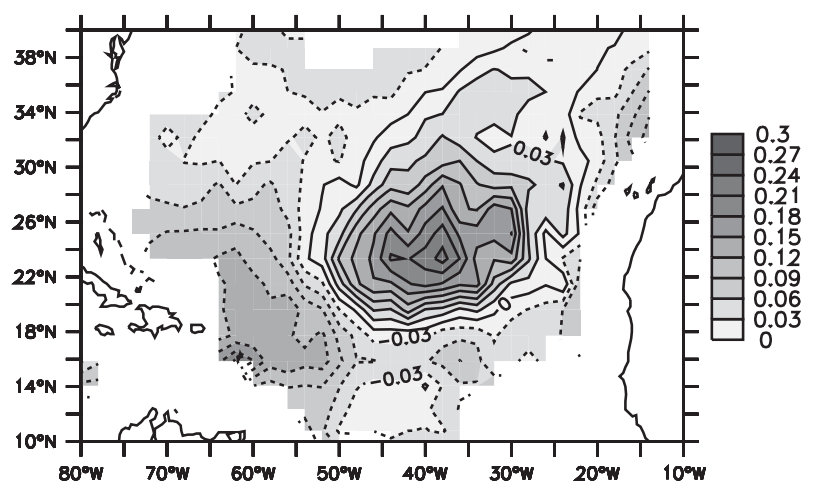

b) SSTA (composite)

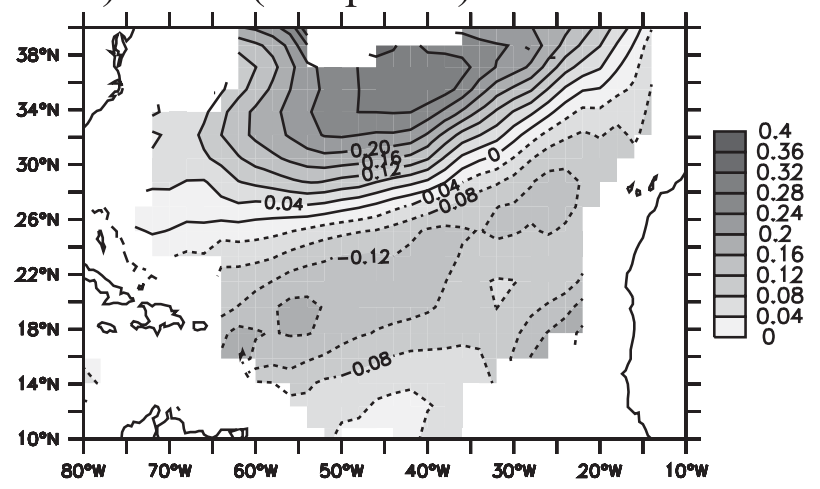

d) $R_{S, T}$ SSTA (composite)

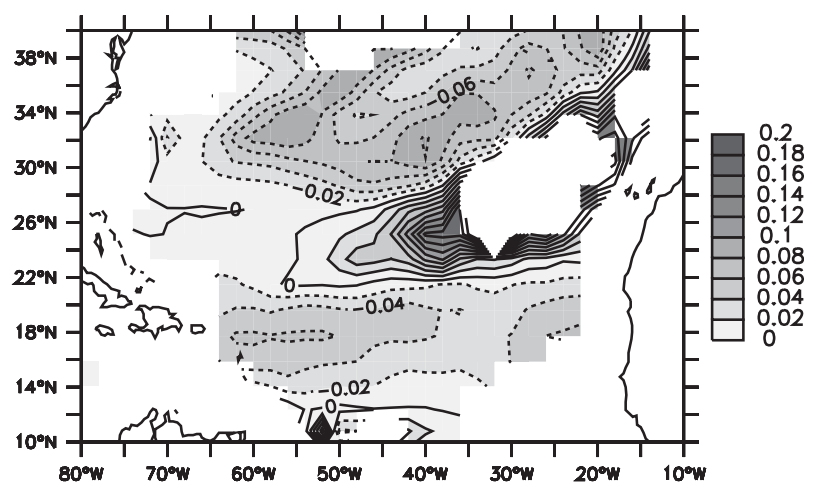

f) Reconstructed ISA (composite)

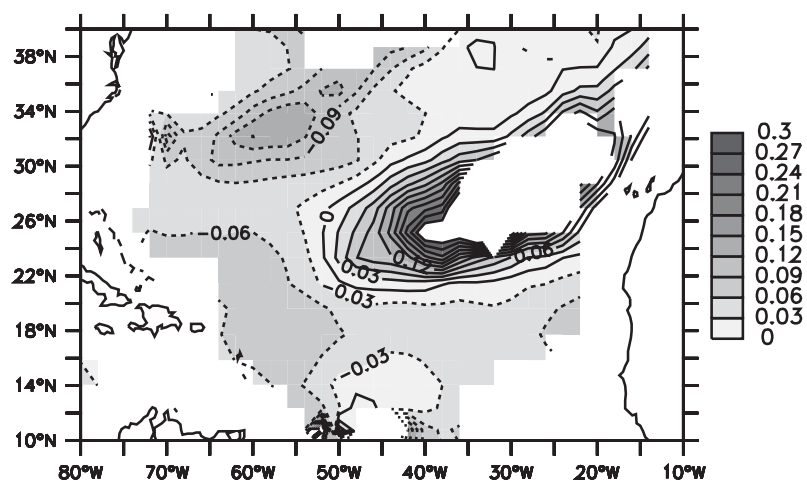

Further analyses using higher-resolution simulations are underway to address the robustness of this decadal variability, which may well be an artificial feature related to the coarse resolution and the forcing errors of the simulation. Moreover, to determine if this formation mechanism is indeed observed in the global ocean, long time series of temperature and salinity in the upper oceans are required and they are beginning to be collected as part of the Argo project. Another issue related to these subducted spiciness anomalies is whether the spiciness anomalies generated in the SMW region of the
North Atlantic subtropical gyre have an impact on climate when they obduct or not.

Acknowledgments. We thank K. Rodgers for providing the OGCM simulation. Fruitful discussions with J. Mignot and colleagues at IPRC and KNMI are acknowledged. We also thank the two anonymous reviewers for their constructive criticisms. This work was supported by a grant from the Programme National d'Etude de la Dynamique du Climat of the Institut National des Sciences de l'Univers. 


\section{APPENDIX A}

\section{Seasonal Cycle of the SSS in the Formation Region of the Spiciness Anomalies}

At the seasonal time scale, the SSS in the formation region is mainly controlled by the seasonal evaporation minus precipitation $(E-P)$ rate and the horizontal advection of SSS (not shown). The seasonal $E-P$ term is positive all year long and reaches its maximum in summer. Indeed, the region is too far north to be directly influenced by the precipitation associated with the latitudinal displacements of the ITCZ, and thus evaporation is the dominant term (on the order of $127.5 \mathrm{~cm} \mathrm{yr}^{-1}$, cf. 23 $\mathrm{cm} \mathrm{yr}^{-1}$ for the precipitation rate, not shown). The seasonal horizontal advection of SSS is negative all year long because fresh waters from the ITCZ region is brought in the formation region by Ekman transport. This freshwater transport is most efficient from August through September when the ITCZ is at its northernmost position. These results are consistent with the seasonal salt budget at $15^{\circ} \mathrm{N}, 38^{\circ} \mathrm{W}$ based on in situ observations analyzed by Foltz et al. (2004). At $15^{\circ} \mathrm{N}$, however, the $E-P$ term is more influenced by precipitation associated with the ITCZ than in the formation region. This climatological SSS budget is also consistent with numerical results based on the ECHAM4/OPA8 coupled model (Mignot and Frankignoul 2003).

\section{APPENDIX B}

\section{Comparison between the Analytical Model of Nonaka and Sasaki (2007) and Ours}

The analytical model given by expressions (7) is more general than that of Nonaka and Sasaki (2007) because it includes a more general direction of the displacement of the outcropping isopycnal surfaces. The realism of the analytical prognostic ISAs given by Eq. (7) is enhanced when considering a general displacement of the outcropping isopycnals (dl) instead of a meridional displacement, as shown in Fig. B1. The rms error induced by using a meridional displacement instead of a general displacement dl for the month following the month of maximum MLD over the period of 1948-2002 is about $5 \%$, especially in regions where the surface displacement $\mathbf{d l}$ is not meridional; that is, mainly in the SMW area and northeast of it. The analytical model discussed in this paper allows a more complete understanding of the generation mechanism of spiciness anomalies and it thus further characterizes the ventilation of the North Atlantic subtropical gyre.

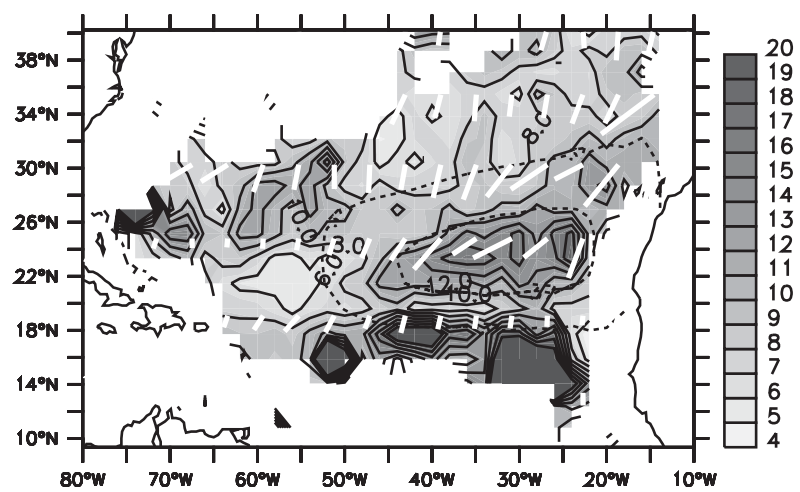

FIG. B1. Root-mean-square error (\%) between the analytical isopycnal salinity anomalies computed using expression (7) and the corresponding analytical isopycnal salinity anomalies using a meridional displacement. The computation is done for anomalies located under the base of the mixed layer during the month following the month of maximum mixed layer depth. The white segments indicate the direction and amplitude of the mean winter displacement of outcropping isopycnal surfaces shown in Fig. 3. The obduction regions are masked using the annual mean ventilation rate shown in Fig. 5, and the mean winter maximum sea surface salinity is highlighted by the isohalines 37 and 37.4 psu (dotted contours).

\section{REFERENCES}

Bindoff, N. L., and T. J. McDougall, 1994: Diagnosing climate change and ocean ventilation using hydrographic data. $J$. Phys. Oceanogr., 24, 1137-1152.

Blanke, B., and P. Delecluse, 1993: Variability of the tropical Atlantic Ocean simulated by a general circulation model with two different mixed layer physics. J. Phys. Oceanogr., 23, 1363-1388.

— , M. Arhan, A. Lazar, and G. Prévost, 2002: A Lagrangian numerical investigation of the origins and fates of the salinity maximum water in the Atlantic. J. Geophys. Res., 107, 3163, doi:10.1029/2002JC001318.

Boyer, T. P., S. Levitus, J. Antonov, M. Conkright, T. O'Brien, and C. Stephens, 1998: Salinity of the Pacific Ocean. Vol. 5, World Ocean Atlas 1998, NOAA Atlas NESDIS 31, 166 pp.

Church, J. A., J. S. Godfrey, D. R. Jackett, and T. J. McDougall, 1991: A model of sea level rise caused by ocean thermal expansion. J. Climate, 4, 438-456.

Curry, R., B. Dickson, and I. Yashayaev, 2003: A change in the freshwater balance of the Atlantic Ocean over the past four decades. Nature, 426, 826-829.

Foltz, G. R., S. A. Grodsky, J. A. Carton, and M. J. McPhaden, 2004: Seasonal salt budget of the northwestern tropical Atlantic Ocean along $38^{\circ} \mathrm{W}$. J. Geophys. Res., 109, C03052, doi:10.1029/2003JC002111.

Gent, P. R., and J. C. McWilliams, 1990: Isopycnal mixing in ocean circulation models. J. Phys. Oceanogr., 20, 150-156.

Jackett, D. R., and T. J. McDougall, 1985: An oceanographic variable for the characterization of intrusions and water masses. Deep-Sea Res., 32, 1195-1207.

Johnson, G. C., 2006: Generation and initial evolution of a mode water $\theta-S$ anomaly. J. Phys. Oceanogr., 36, 739-751.

Kalnay, E., and Coauthors, 1996: The NCEP/NCAR 40-Year Reanalysis Project. Bull. Amer. Meteor. Soc., 77, 437-471. 
Kessler, W. S., 1999: Interannual variability in the subsurface high salinity tongue south of the equator at $165^{\circ}$ E. J. Phys. Oceanogr., 29, 2038-2049.

Latif, M., E. Roeckner, U. Mikolajewicz, and R. Voss, 2000: Tropical stabilization of the thermohaline circulation in a greenhouse warming simulation. J. Climate, 13, 18091813.

Laurian, A., A. Lazar, G. Reverdin, K. Rodgers, and P. Terray, 2006: Poleward propagation of spiciness anomalies in the North Atlantic Ocean. Geophys. Res. Lett., 33, L13603, doi:10.1029/2006GL026155.

Lazar, A., R. Murtugudde, and A. J. Busalacchi, 2001: A model study of temperature anomaly propagation from the subtropics to tropics within the South Atlantic thermocline. $G e$ ophys. Res. Lett., 28, 1271-1274.

- T. Inui, P. Malanotte-Rizzoli, A. J. Busalacchi, L. Wang, and R. Murtugudde, 2002: Seasonality of the ventilation of the tropical Atlantic thermocline in an ocean general circulation model. J. Geophys. Res., 107, 3104, doi:10.1029/ 2000JC000667.

Luo, Y., L. M. Rothstein, R.-H. Zhang, and A. J. Busalacchi, 2005: On the connection between South Pacific subtropical spiciness anomalies and decadal equatorial variability in an ocean general circulation model. J. Geophys. Res., 110, C10002, doi:10.1029/2004JC002655.

Luyten, J. R., J. Pedlosky, and H. Stommel, 1983: The ventilated thermocline. J. Phys. Oceanogr., 13, 292-309.

Madec, G., P. Delecluse, M. Imbard, and C. Lévy, 1998: OPA 8.1 ocean general circulation model reference manual. Institut Pierre Simon Laplace Note 11, 91 pp.

Marshall, J. C., A. J. Nurser, and R. G. Williams, 1993: Inferring the subduction rate and period over the North Atlantic. $J$. Phys. Oceanogr., 23, 1315-1329.
Mignot, J., and C. Frankignoul, 2003: On the interannual variability of surface salinity in the Atlantic. Climate Dyn., 20, 555565, doi:10.1007/s00382-002-0294-0.

Munk, W., 1981: Internal waves and small-scale processes. Evolution of Physical Oceanography, B. A. Warren and C. Wunsch, Eds., MIT Press, 264-291.

Nonaka, M., and S. P. Xie, 2000: Propagation of North Pacific interdecadal subsurface temperature anomalies in an ocean GCM. Geophys. Res. Lett., 27, 3747-3750.

- , and H. Sasaki, 2007: Formation mechanism for isopycnal temperature-salinity anomalies propagating from the eastern South Pacific to the equatorial region. J. Climate, 20, 1305-1315.

Reverdin, G., E. Kestenare, C. Frankignoul, and T. Delcroix, 2007: Surface salinity in the Atlantic Ocean $\left(30^{\circ} \mathrm{S}-50^{\circ} \mathrm{N}\right)$. Prog. Oceanogr., 73, 311-340, doi:10.1016/j.pocean.2006.11.004.

Rudnick, L. R., and R. Ferrari, 1999: Compensation of horizontal temperature and salinity gradients in the ocean mixed layer. Science, 283, 526-529.

— and J. P. Martin, 2002: On the horizontal density ratio in the upper ocean. Dyn. Atmos. Oceans, 36, 3-21.

Schneider, N., 2000: A decadal spiciness mode in the tropics. Geophys. Res. Lett., 27, 257-260.

Stommel, H., 1979: Determination of water mass properties of water pumped down from the Ekman layer to the geostrophic flow below. Proc. Natl. Acad. Sci. USA, 76, 3051-3055.

Tailleux, R., A. Lazar, and C. J. C. Reason, 2005: Physics and dynamics of density-compensated temperature and salinity anomalies. Part I: Theory. J. Phys. Oceanogr., 35, 849-864.

Yeager, S. G., and W. G. Large, 2004: Late-winter generation of spiciness on subducted isopycnals. J. Phys. Oceanogr., 34, $1528-1547$.

_ and - 2007: Observational evidence of winter spice injection. J. Phys. Oceanogr., 37, 2895-2919. 